${ }^{1}$ Cahyo Setiadi Ramadhan, ${ }^{2}$ Imam

Suprabowo, ${ }^{3}$ Wulan Noviani

${ }^{1}$ Fakultas A gama Islam, ${ }^{2,3}$ Fakultas

Kedokteran, dan IImu Kesehatan

Universitas M uhammadiyah Yogyakarta

Jalan Brawijaya, Tamantirto, Kasihan,

Bantul, Yogyakarta 55183

Email: cahyosetiadi@umy.ac.id

\section{Pengembangan Mi Lethek Sebagai Kuliner Unggulan Bantul}

The Development Of Mi Lethek As Bantul's Superior Culinary Product

https:/ / doi.org/ 10.18196/ bdr.7263

\begin{abstract}
Mi Lethek (Lethek Noodle) is made from Bantul original cassava. Its selling creation and packaging are potentially developed. The objective to develop Mi Lethek noodle is to increase the added value and selling value of Bantul's superior culinary product. The method used was providing training and coaching on the selling tips and creative packaging, monitoring and evaluation towards the producers and the management. The results obtained are the producer label establishment of Mi Lethek Asli Bendo with Garuda brand, the noodle product with new packaging, and online marketing media.

Keywords: Mi Lethek, superior culinary, Bantul
\end{abstract}

\title{
PENDAHULUAN
}

Mi lethek merupakan salah satu produk kuliner lokal khas Bantul (Tribun Jogja, 2019). Produk ini berbahan dasar singkong yang diolah menjadi tepung lalu dicetak menjadi mi. Produk ini memiliki peluang untuk bersaing sebagai sebuah produk kuliner. M isalnya, O bama mengenal dan menyukai mi ini (Tim Viva, 2017). Proses pembuatan mi lethek masih konvensional, yaitu menggunakan metode lama. Proses pembuatan ini menjadikan sebagian orang menganggap mi ini lebih sehat dari mi yang dibuat pabrik dengan mekanisasi. Sebagian menyebut produk ini sebagai mi organik karena proses produksi tersebut.

Pada sisi lain, proses pembuatan dengan cara lama membuat produsen kesulitan untuk mengembangkan pasar. Selain itu, proses pembuatan cara lama tersebut menjadikan produsen juga perlu mengeluarkan biaya banyak (Sigit, 2018, Tim Viva, 2017). Oleh karena itu produsen tertarik mengembangkan cara produksinya menjadi lebih mekanik. $\mathrm{H}$ al ini dapat mendorong keefektifan produksi. Tetapi di sisi lain, akan mengurangi ten aga kerja yang tidak sejalan dengan filosofi didirikannya beberapa pabrik mi lethek di masa dahulu. 


\section{3}

Selain proses pembuatan, terdapat hal lain yang dapat dikembangkan dari industri mi lethek. Dalam hal aspek pengemasan, produsen mi lethek masih menggunakan cara pembungkusan lama juga. Mi seberat $5 \mathrm{~kg}$ dibungkus dengan kemasan plastik dengan disertai flyer atau selembar kertas dengan merk, P-IRT, dan slogan lain. $\mathrm{H}$ al ini dikarenakan pangsa pasar pabrik cenderung pedagang masakan mi lethek sehingga akan membeli dengan porsi banyak. $\mathrm{H}$ al ini menjadi kurang menarik bagi pelanggan umum karena faktor warna dan gambar memengaruhi ketertarikan calon pembeli untuk membeli (Ahmad, M ohibBillo, \& Lakhan, 2012).

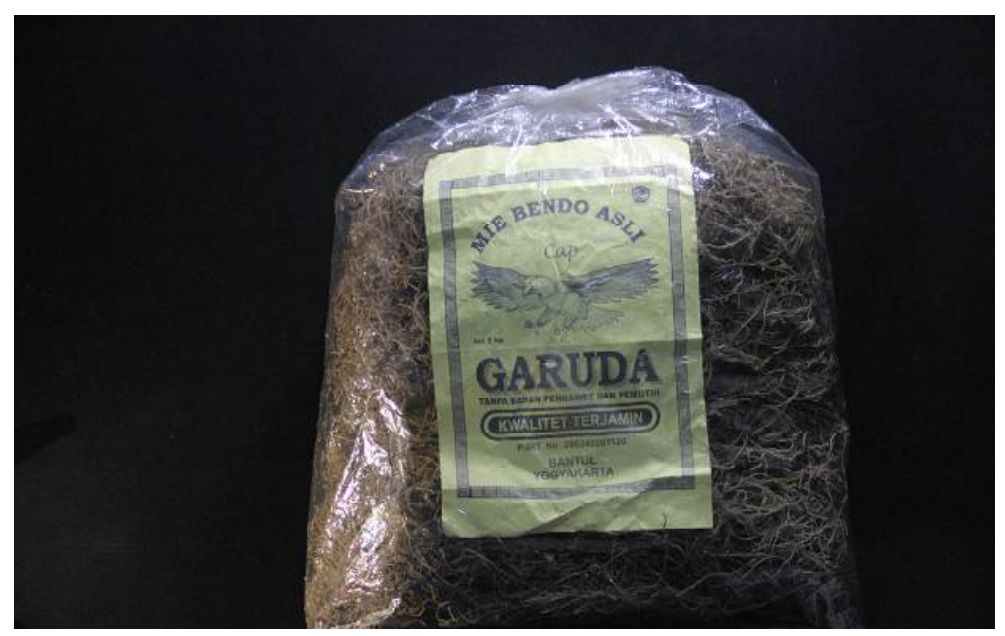

Gambar 1. Kemasan Lama

Faktor lain yang dapat ditingkatkan dari produsen mi lethek yaitu mengenai cara penjualan. Produsen mi lethek pada umumnya masih men ggunakan cara penjualan yang tradisional. Pembeli mendapatkan informasi mengenai produsen mi dari informasi lingkungan sosialnya atau dari mulut kemulut. Kondisi ini tentu memerlukan perbaikan untuk dapat sesuai dengan kondisi kekinian. Masyarakat telah mengalami perubahan perilaku dan lebih akrab dengan media baru atau media digital. Kondisi ini tentu perlu diimbangi juga dengan mengadakan sistem pemasaran yang digital atau dalam jaringan dunia maya. Mengimbangi perubahan masyarakat menjadi nirkabel akan membantu penjualan produk mi dan memasyarakatkan mi (Schwarzl dan Grabowska, 2015).

U ntuk itu, akan dilakukan usaha revitalisasi atau peningkatan kualitas dan daya jual produk mi lethek sebagai warisan kuliner Bantul. Dalam upaya tersebut, dapat dipilih salah satu produsen mi lethek yang dapat menjadi model bagi rekan yang lain. D engan adanya model, produsen lain dapat terdorong untuk melakukan revitalisasi (Bandura, 1971). Selain itu, revitalisasi mi lethek yang terjadi pada suatu kelompok dapat berkembang ke kelompok lainnya yang masih berkaitan dengan mi lethek. Ini sesuai dengan teori 
Bronfrenbrenner (1977) yang menyatakan bahwa komunitas merupakan serangkaian sistem yang saling memengaruhi.

Produsen mi yang akan menjadi sasaran revitalisasi merupakan produsen mi lethek yang sudah lama beroperasi yaitu sejak 1940. Produsen mi tersebut memiliki ikatan sejarah dan kebudayaan yang kuat dengan Yogyakarta dan Bantul. Selain itu, produsen tersebut juga memiliki ikatan sejarah yang kuat dengan republik sehingga dinamakan $\mathrm{G}$ aruda. Termasuk kaya dengan nilai-nilai nasionalisme sehingga sei ring dengan produknya yang merupakan warisan budaya luhur masyarakat Bantul.

Sebagaimana yang telah dijelaskan, bah wa pen gembangan pengemasan menjadi sasaran utama. Faktor pengemasan memang menjadi faktor pendorongyang dapat memunculkan ketertarikan calon pembeli untuk menjadi pembeli (A bdalkrim dan Al-H rezat, 2013). Pengemasan telah lama dikenal sebagai salah satu cara untuk menambah nilai jual produk (Bassin, 1988). Selain itu, perlu dikembangkan juga sistem penjualan online. Sistem penjualan online dapat membantu pengenalan produk. Selain itu sistem tersebut juga dapat menambah nilai dan meningkatkan penerimaan pada masyarakat (Jiao, Gao, dan Yang, 2015).

\section{M etode Pelaksan aan}

Untuk dapat mendorong produsen melakukan perubahan, perlu disusun langkahlangkah pengantarnya. Bentuk pengantar individu untuk memunculkan perilaku baru atau mempelajari hal baru, diperlukan pengetahuan mengenai hal tersebut dan kemudian kesempatan untuk mencobanya (Bandura, 1971, 1977). Tidak kalah penting yaitu menumbuhkan kesertaannya dalam perubahan (A rcher, et al.; 1984; C avaye, 2015; Flora dan Flora; 1993). Berdasarkan pandangan tersebut, disusun metode pelaksanaan program sebagai berikut.

1. Sosialisasi program dan manfaat serta cara pelaksanaan program kepada produsen. $\mathrm{H}$ al ini diperlukan karena sebagaimana yang disampaikan sebelumnya bahwa penting dalam pemberdayaan masyarakat mereka dilibatkan (A rcher, et al.; 1984; C avaye, 2015; Flora \& Flora; 1993). Dalam hal ini pengusul akan menyediakan fasilitator yang mengarahkan jalannya diskusi berhujung pada peningkatan daya jual produk mi lethek.

2. Produsen mendapatkan edukasi peningkatan daya jual produk taninya melalui proses edukasi dan pendampingan hingga ke tahap praktik. Sebagaimana yang disebutkan pengetahuan diperlukan untuk peningkatan kapasitas (C avaye, 2015).

3. Experential Learning peningkatan daya jual yang merupakan proses praktik edukasi 


\section{5}

yang telah dilakukan. U ntuk itu, produsen menjalankan langkah yang telah diketahui dari proses edukasi secara terbimbing. Proses ini efektif untuk pemula yang sedang melakukan peningkatan kapasitas diri (Correy, 2012; M iltenberger, 2015). Terjadinya peningkatan kapasitas produsen menunjukkan tercapainya tujuan program, yaitu kemampuan menjalankan metode penjualan baru dan pengemasan yang baik.

Walaupun tujuan program telah tercapai, tetapi kepada masyarakat dalam hal ini produsen, masih dapat dilakukan berbagai hal yaitu peningkatan gizi, sertifikasi halal, dan mi lethek masuk pasar modern.

\section{HASIL DAN PEMBAHASAN}

Waktu need assessment awal yangsingkat menjadikan terdapat data-datayang terlewatkan sehingga menimbulkan perubahan dalam pelaksanaan program. Ini seharusnya bukan kendala yang besar karena proses dalam program di masyarakat terlihat seperti siklus dalam A ction Research yang sirkular (Koentjoro, Sadewo, dan Andayani, 2016, Velasco, 2013). A dapun gambaran pelaksanaan kegiatan sebagai berikut.

1. Konsolidasi dan Edukasi Tim Pengusul dan Produsen

Konsolidasi dilakukan secara informal beberapa kali kepada produsen yang menjadi sasaran program. Selain konsolidasi juga dilakukan diskusi sebagai edukasi. Proses edukasi dilakukan dalam bentuk diskusi karena yang dihadapi adalah individu tunggal dewasa. Kegiatan edukasi dilakukan dua kali yaitu lanjutan konsolidasi awal pada 2 Februari 2019 dan pada tanggal $16 \mathrm{M}$ aret 2019.

Pada tanggal 2 Februari 2019, diskusi dilakukan mengenai peningkatan daya jual melalui perubahan kemasan dan sistem penjualan. Produsen telah memahami pentingnya perubahan pengemasan dan proses penjualan kemudian sepakat untuk melakukannya. Produsen mengharapkan adanya proses percontohan terlebih dahulu. U ntuk itu, dalam proses edukasi dilakukan juga kegiatan percontohan (modelling). Untuk itu, pengabdi akan melakukan kegiatan pengemasan baru terlebih dahulu dan mencoba memperluas penjualan sebelum kegiatan tersebut diterapkan pada mitra. Disepakati, produk yang diperbaharui secara kemasan dan penjualan sebanyak 100 bungkus.

\section{Desain Pengemasan Baru}

U ntuk merancang pengemasan baru pelaksana mencari desainer dari kalangan mahasiswa untuk menambah pengalaman dan portofolio mahasiswa tersebut. Pengabdi melakukan pencarian sejak 13 Februari 2019 namun baru mendapatkan mahasiswa yang 
mampu dan bersedia mendesain kemasan baru untuk mi lethek pada 28 Februari 2019. Proses desain pengemasan berlangsung sejak tanggal tersebut hingga sekarang dikarenakan berbagai perubahan.

D esain diarahkan menampilkan bentuk mi yang telah dimasak untuk menarik pembeli, menampilkan label halal, label izin usaha, nama produsen, dan bahan baku. Selain itu, desain diharapkan bernuansa jawa dan dapat menunjukkan kesan asli Bantul sehingga semakin mungkin produk untuk dianggap sebagai oleh-oleh khas Bantul.

Sejak 13 Februari 2019 pengabdi melakukan pemilihan merk agar dapat mendukung nuansa Jawa khas Bantul. Pada tanggal 1 M aret 2019 dilakukan pememilihan nama dan huruf untuk merek. D ipilih merk "Thukul”, yang merupakan singkatan Lethek Bantul. Ditetapkan juga slogan “M i Lethek Khas Bantul” untuk memperkuat kesan asli Bantul.

Pada 5 M aret 2019 dihasilkan beberapa pilihan desain. Pada tanggal 14 M aret 2019 dilakukan perubahan label halal karena belum ada rencana pengajuan label halal kepada MU I pada tahapan pengabdian ini. Selain itu merek ditambah dengan kata "M i" untuk menambah kuat kesan sebagai produk makanan karena nama "Thukul" identik dengan pelawak.

D esain segera didiskusikan dengan produsen selaku sasaran program pada $16 \mathrm{M}$ aret 2019. Diskusi menghasilkan perubahan merek menjadi "M iN do", merupakan singkatan dari "M i Bendo" yang merupakan namalain dari mi lethek. Tagline diubah menjadi "M i Bendo Khas Bantul". Selain untuk memperkuat kesan merek, tidak dicampuri kesan yang sudah ada seperti pada merek "Thukul", memperkuat kelekatan dengan Bantul dan daerah asal, dan juga menghindari kesan negatif "Lethek" yang berasal dari Bahasa Jawa berarti kotor. Selain itu saran penyajian mi juga akan ditampilkan dalam kemasan.

\section{Perubahan Alat Produksi}

Berdasarkan hasil diskusi pada 16 Maret 2019 dan praktisi pengemasan (Dani D ardanela dari Pojok Kemasan) pada $6 \mathrm{M}$ aret, perlu dirancang al at yang dapat membuat mi memadai untuk dikemas. $\mathrm{H}$ asil produksi selama ini tidak memungkinkan mi untuk dikemas. Alat tersebut pengabdi rancang dan pesan dari pengrajin loyang. Pemesanan kepada pengrajin loyang mempertimbangkan bahwa mi yangakan diproduksi merupakan makanan sehingga pengrajin loyang yang juga biasa digunakan untuk membuat makanan memahami bahan yang aman. 


\section{7}

\section{Pembaharuan Bahan Kemasan}

Untuk pembaharuan bahan kemasan, dicari praktisi pengemasan untuk mengonsultasikan bahan kemasan baru. Praktisi pengemasan yaitu $D$ ani Dardanela dan Pusat Kemasan UKM. Diskusi dilakukan pada 10 Februari 2019 dan 6 Maret 2019. Diskusi menghasilkan pengetahuan mengenai hal-hal yang perlu ditampilkan pada kemasan serta perizinan yang perlu diperoleh, bagi suatu produk untuk dijual secara bebas. Selain itu, diskusi menghasilkan alternatif pilihan bahan kemasan yang aman, terlihat menarik, sesuai dengan rancangan, dan attainable bagi program. Kemasan baru seukuran kemasan produk mi instan karena produk yang akan dihasilnya meniru ukuran mi instan. A dapun kemasan yangakan diproduksi yaitu lebar 10,5 - $14 \mathrm{~cm}$ dan panjang $15-17 \mathrm{~cm}$.

Perbedaan ukuran tersebut dikarenakan ada 3 kemasan yang diproduksi. M elalui bantuan praktisi tersebut diproduksi sekitar 50 bungkus kemasan baru yang sederhana. Pengabdi juga melakukan survei mandiri ke produsen kemasan bagi usaha kecil yaitu Pojok Kemasan U M KM dan memproduksi dua jenis kemasan baru yaitu masing-masing 50 bungkus. Sehingga didapatkan 100 bungkus kemasan mi lethek yang baru.

\section{Pengemasan}

Setelah kemasan baru dicetak, maka dilakukan proses produksi dan pengemasan. Produksi menggunakan alat produksi yang baru. Sedangkan pengemasan dibantu dengan penutupan seal di Pusat Kemasan U KM .

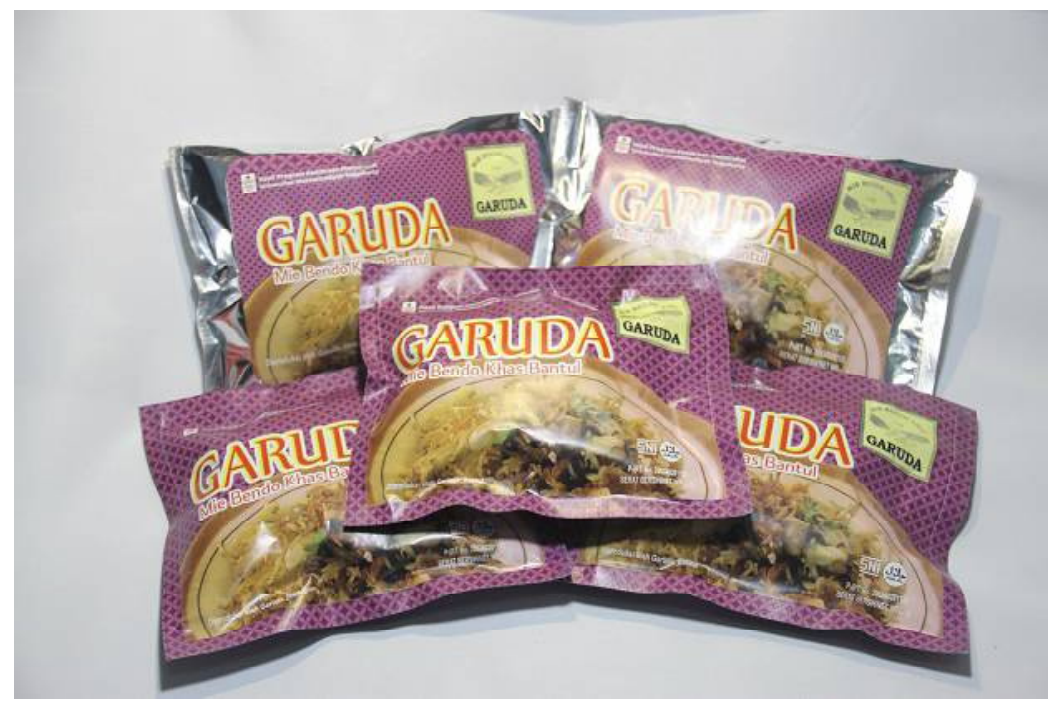

Gambar 2. Kemasan Baru 
6. Perluasan Penjualan

Kegiatan ini dilakukan dengan menggunakan media sosial untuk melakukan penjualan. Pengabdi berkonsultasi pada $24 \mathrm{M}$ aret 2019 dengan praktisi penjualan online. Selain itu telah dibuat laman dan berbagai media online untuk media promosi.

\section{Supervisi Mitra}

Supervisi Kelompok U saha dilakukan setelah proses pemodelan. Proses pemodelan dilakukan dengan produksi dan penjualan produk Mi Bendo dalam kemasan yang dibimbing oleh pengabdi. Pada masa supervisi tersebut, tidak terjadi lonjakan signifikan dalam penjualan Mi Bendo dalam kemasan. Berdasarkan pencatatan penjualan yang dilakukan, sebulan terjual 10 bungkus mi. Dapat dikatakan strategi yang ditawarkan tidak mendapatkan hasil sesuai harapan.

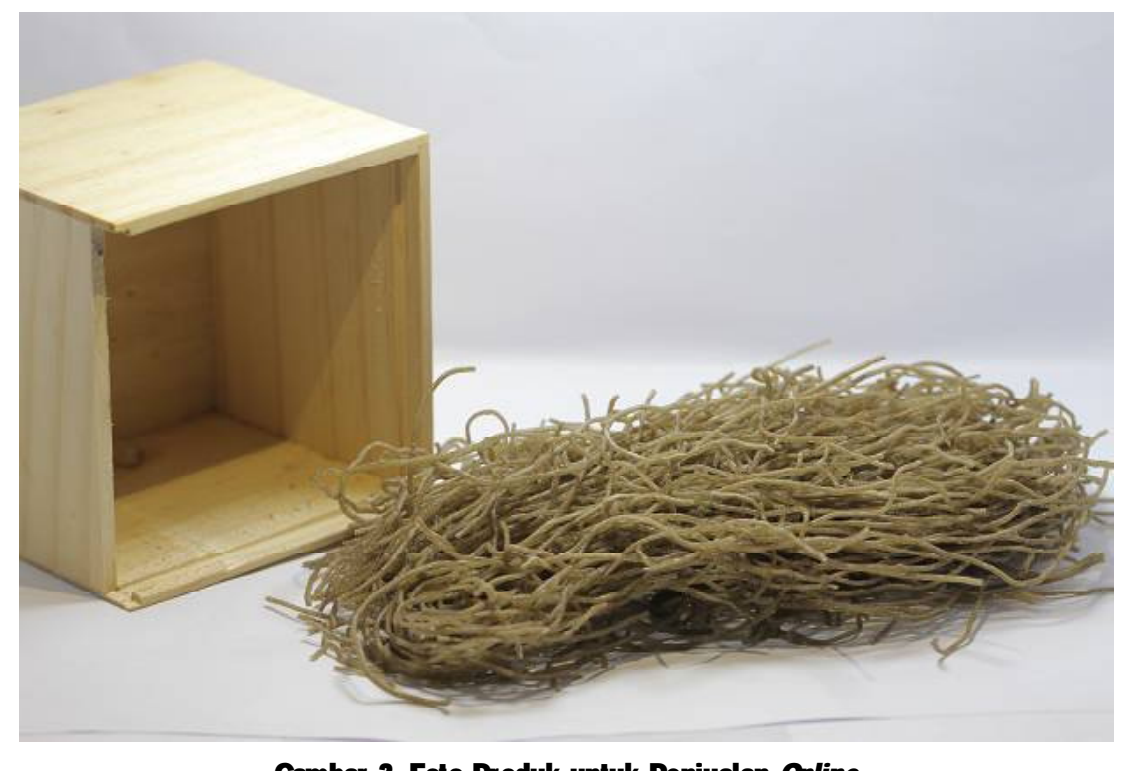

Gambar 3. Foto Produk untuk Penjualan Online

Berdasarkan penjabaran sebelumnya diketahui bahwa target program dapat tercapai, yaitu dapat diproduksi produk M i Bendo kemasan kecil. Walaupun demikian revitalisasi produk mi lethek belum dicapai dalam jangka waktu program ini. Revitalisasi menggunakan media sosial atau mediainternet dapat dilakukan setelah perbaikan produk (Li, Cui, Chen, dan Zhou, 2019). Namun sebagaimana strategi pemasaran lainnya, penggunaan media internet tidak selalu memberikan hasil yang memuaskan (Smith, 2003). Faktor fokus pasar menjadi salah satu faktor keberhasilan penggunakan media internet untuk penjualan ataupun revitalisasi produk (Bala dan Verma, 2018, Thomas dan Kohli, 2009). 


\section{9}

\section{SIM PULAN}

Berdasarkan penjelasan sebelumnya diketahui bahwa target program dapat tercapai, yaitu dapat diproduksi produk M i Bendo kemasan kecil. Walaupun demikian revitalisasi produk mi lethek dapat dikatakan tidak tercapai dalam jan gka waktu pelaksanaan program pen gabdian. Faktor fokus pasar yang kurang ditekankan menjadi hal yang dapat berperan dalam revitalisasi produk yang belum tercapai. Berdasarkan simpulan tersebut dapat disarankan kepada pengabdi untuk dapat merencanakan program revitalisasi produk dengan memperhatikan secara saksama pangsa pasar yang akan disasar agar dapat memilih media internet yang sesuai.

\section{UCAPAN TERIMA KASIH}

U capan terima kasih disampaikan kepada berbagai pihak yang telah mendukung terlaksananya kegiatan ini. U capan terima kasih pertama khusus untuk Lembaga Penelitian, Publikasi dan Pengabdian M asyarakat (LP3M) U niversitas M uhammadiyah Yogyakarta yang telah membiayai kegiatan ini. Selain itu disampaikan terimakasih kepada masyarakat Poncosari yang bersedia membantu dalam proses dengan memberikan informasi. Terima kasi h terutama disampaikan kepada Yasir Feri I smatrada dan segenap keluarga besar Pabrik Mi Lethek Asli Bendo Cap Garuda di Pedukuhan Bendo, Desa Trimurti, Srandakan, Bantul yang bersedia menjadi mitra dan melakukan program yang disarankan.

\section{DAFTAR PUSTAKA}

Abdalkrim, G. M., \& Al-Hrezat, R.S. 2013. "The Role of Packaging in Consumer's Perception of Product Quality at the Point of Purchase". European Journal of Business and Management, 5(4).

Ahmad, N., MohibBillo, dan Lakhan, A. 2012. "Effect of Product Packaging in Consumer Buying Decision". Journal of Business Strategies, 6 (2): 1-10.

Archer, S. E., Kelly, C. D., dan Bisch, S. A. 1984. Planning and Change Processes. Implementing Change in Communities: A Collaborative Process (pp. 21-50). St. Louis: The C.V. Mosby Company.

Bala, M., \& Verma, D. 2018. A critical review of digital marketing. International Journal of Management, IT \& Engineering, 8(10): 321-329.

Bassin, S. B .1988. "Packaging: A key element in added value". J ournal of Food Distribution Research, 19(1): 6 .
Cavaye, J. 2015. Understanding Community Development. Quensland: Cavaye Community Development.

Correy, G. 2012. Theories and Practice of Counselling and Psychotherapy. Belmont: Brooks-Cole Cengage Learning.

Flora, C.B., \& Flora, J.L. 1993. "Entrepreneurial Social Infrastructure: A Necessary Ingredient". Annals of the American Academy of Political and Social Sciences 539: 48-58.

J iao Y., Gao, J., Yang, J. 2015. "Social value and content value in social media: Two ways to flow". Journal of Advanced Management Science, 3 (4): 299-306.

Koentjoro, Sadewo, P. H., Andayani, B. 2016. Community Engagement or Community Development. Presentasi pada The 10th Global Regional Centres of Expertise on Education for Sustainable 
Development (RCEs on ESD) 23 - 25 November 2016, Universitas Gadjah Mada, Yogyakarta, Indonesia.

Li, C., Cui, Z., Chen, J., dan Zhou, N. 2019. Brand revitalization of heritage enterprises for cultural sustainability in the digital era: A case study in china. Sustainability, 11: 1769, doi:10.3390/ su11061769.

Miltenberger, E.G. 2015. Behavior Modification: Principles and Procedures. Belmont: Cengage Learning.

Schwarzl S., dan Grabowska, M. 2015. "Online marketing strategies: the future is here". Journal of International Studies, 8(2): 187-196. DOI: 10.14254/2071-8330.2015/8-2/16

Sigit, A. 2019. Mi Lethek, Mi Legendaris Bantul yang Tidak Se'lethek' Namanya. Diakses pada 22 J uni 2019 di https://krjogja.com/web/news/read/ 90884/Mi_Lethek_Mi_Legendaris_Bantul_yang_Tidak_Se_lethek_Namanya.

Smith, B. 2003. "Success and failure in marketing strategy making: Results of an empirical study across medical markets". International Journal of Medical Marketing, 3(4): 287-315.

Thomas, S., dan Kohli, C. 2009. "A brand is forever! A framework for revitalizing declining and dead brands". Business Horizons, 52: 377-386.

TimVivo. 2017. Pengusaha Mi Lethek Bantul Kewalahan Gara-gara Barack Obama. Diakses pada 22 J uni 2019 di www.viva.co.id/gaya-hidup/ kuliner/944183-pengusaha-mi-lethek-bantulkewalahan-gara-gara-barack-obama.

Tribun Jogja. 2019. Rekomendasi 5 Warung Mi Lethek Enak di Bantul. Diakses pada 22 Juni 2019 di https://jogja.tribunnews.com/2019/01/ 25/rekomendasi-5-warung-mi-lethek-enak-dibantul?page $=3$. 